\title{
High resolution climate projection of storm surge at the Venetian coast
}

\author{
R. Mel ${ }^{1}$, A. Sterl ${ }^{2}$, and P. Lionello ${ }^{3,4}$ \\ ${ }^{1}$ DICEA (Dipartimento di Ingegneria Civile, Edile ed Ambientale), University of Padova, Italy \\ ${ }^{2}$ KNMI (Royal Netherlands Meteorological Institute), De Bilt, the Netherlands \\ ${ }^{3}$ DISTEBA (Dipartimento Scienze e TEcnologie Biologiche e Ambientali), University of Salento, Lecce, Italy \\ ${ }^{4} \mathrm{CMCC}$ (Euro-Mediterranean Center on Climate Change), Lecce, Italy
}

Correspondence to: R. Mel (riccardo.mel@dicea.unipd.it)

Received: 6 November 2012 - Published in Nat. Hazards Earth Syst. Sci. Discuss.: -

Revised: 4 March 2013 - Accepted: 12 March 2013 - Published: 30 April 2013

\begin{abstract}
Climate change impact on storm surge regime is of great importance for the safety and maintenance of Venice. In this study a future storm surge scenario is evaluated using new high resolution sea level pressure and wind data recently produced by EC-Earth, an Earth System Model based on the operational seasonal forecast system of the European Centre for Medium-Range Weather Forecasts (ECMWF). The study considers an ensemble of six $5 \mathrm{yr}$ long simulations of the rcp45 scenario at $0.25^{\circ}$ resolution and compares the 20942098 to the 2004-2008 period. EC-Earth sea level pressure and surface wind fields are used as input for a shallow water hydrodynamic model (HYPSE) which computes sea level and barotropic currents in the Adriatic Sea. Results show that a high resolution climate model is needed for producing realistic values of storm surge statistics and confirm previous studies in that they show little sensitivity of storm surge levels to climate change. However, some climate change signals are detected, such as increased persistence of high pressure conditions, an increased frequency of windless hour, and a decreased number of moderate windstorms.
\end{abstract}

\section{Introduction}

Sea level rise and increased storminess are among the major environmental concerns for coastal towns, such as Venice, at the shore of the Northern Adriatic Sea, where storm surges are often caused by low pressure systems, whose centres are mostly positioned in the northwestern Mediterranean Sea (Robinson et al., 1973; Canestrelli et al., 2001; Trigo and
Davies, 2002; Lionello, 2005; Lionello et al., 2012b). In this case both the pressure gradient and the south-easterly wind (Sirocco) blowing along the main axis of the Adriatic accumulate water at its northern coast producing storm surges, which flood Venice several times every year (Lionello et al., 2012a).

Future sea level rise will very likely increase the frequency of extreme sea levels. During the 20th century, the mean relative sea level in Venice had already increased by $0.3 \mathrm{~m}$. Approximately half of it is due to vertical land motion (see Lionello, 2012 for a synthesis), with two main contributions: local anthropogenic subsidence, mostly caused by the extraction of groundwater in the past, and long-term tectonic vertical motion. While the extraction of ground water has stopped (Bock et al., 2012), tectonic motion is expected to continue, though eventually not at a regular pace. Furthermore, sea level is expected to rise in the future at a pace that, as it depends on the action of many regional factors, is uncertain and cannot be easily related to global sea level rise. Thermosteric expansion, air pressure and wind forcing have been proven to be important for the Mediterranean sea level over the last century and will continue to be relevant for what is going to happen over the 21st century. Specific sources of uncertainty in the Mediterranean Sea are the likely future halosteric contraction and the difficulty to model future mass exchanges between the Mediterranean Sea and Atlantic Ocean (Lionello, 2012; Scarascia and Lionello, 2013).

More extreme sea levels could also be induced by changes in weather extremes, which can imply additional coastal impacts than attributable to sea level rise alone. However, 
changes in storm characteristics and intensity are less certain than sea level rise. Previous studies on storm surge statistic in the Northern Adriatic Sea, which have not found clear indications of significant changes (Lionello et al., 2003, 2012a), were based on relatively low resolution meteorological fields, which were not able to reproduce correctly the statistic of the most extreme events.

The threat of higher water levels due to a combination of mean sea level rise and changing storm characteristics caused by global climate change is of course not limited to the Adriatic Sea, and a vast body of literature investigating future water level changes exists. They all follow the same basic approach used here and separate mean sea level rise and meteorological changes. The reason is that they represent independent effects on water level. The height of a storm surge is substantially independent of mean sea level (e.g. Lowe et al., 2001; Sterl et al., 2009). Wind fields generated by climate models run under increasing greenhouse gas concentrations are then used to drive storm surge models, either directly (e.g. Sterl et al., 2009; How et al., 2012) or after downscaling with a regional climate model (e.g. Woth et al., 2006; Lowe and Gregory, 2008). As it turns out, the results of such exercises depend more on the model used to generate the wind fields than on the scenario used to force the model (Woth et al., 2006; Lowe and Gregory, 2008), suggesting large sensitivity to details of the driving model.

The objective of this paper is to investigate the influence of climate change on storm surge statistics in the Northern Adriatic Sea using a new high resolution climate model simulation, in order to add a new and different contribution to past estimates. It is important to investigate whether a new set of simulations, using meteorological forcing at higher resolution than earlier studies, produces different conclusions. The statistics of sea level, mean sea level pressure (MSLP) and wind, two meteorological variables that is responsible for sea level variations, are analysed with the aim of identifying significant differences between present and scenario conditions.

The paper is organised into 4 sections. Section 2 introduces the climate model EC-Earth, and the storm surge model HYPSE describes the simulations used in this study and discusses their reliability. Section 3 presents a validation of the model results and analyzes the climate change signal in MSLP, wind. Section 4 summarises the main conclusions of this study.

\section{Models and data}

\subsection{EC-Earth model simulations}

Despite their different purposes, climate and weather forecasting are obviously based on the same physical principles. This has been recognised with the introduction of the concept of "seamless prediction", which intends to address the predictability of the climate (in its broadest sense and including multiple time scales) within one common framework. Therefore, EC-Earth was developed (Hazeleger et al., 2010), an Earth System Model based on the operational seasonal forecast system of the European Centre for MediumRange Weather Forecasts (ECMWF). It is intended to investigate Earth system feedbacks, to study inter-annual and multidecadal climate fluctuations and predictability, and to be an advanced modelling tool for computing climate scenarios.

The development of EC-Earth within the EC-Earth consortium started with ECMWF's Integrated Forecast System (IFS) as a well-tested atmospheric module, with different components being added over time. In the current version (V2.3) of EC-Earth an interactive atmosphere-ocean-sea ice coupling is applied across the entire globe, including the polar regions, using different sea ice and land modules.

In a present-day control run the large-scale characteristics of the atmosphere, such as the distributions of MSLP, temperature and humidity are well simulated, as compared to observations, reanalysis data and other coupled atmosphereocean-sea ice models. When forced by increasing concentrations of greenhouses gases to simulate the future climate, EC-Earth shows similar responses as found in earlier model studies: tropospheric warming with a maximum in the higher tropical troposphere, stratospheric cooling, polar amplification of the climate change signal, changes of the hydrological cycle in line with most of IPCC models.

ECEarth has been developed with two kinds of resolution: one low resolution version (LRV), with a grid step of $1.125^{\circ}$, and one high resolution version (HRV), with $0.25^{\circ}$ of grid step. Besides the resolution, the two versions also differ by the kind of coupling: LRV is a fully coupled climate model, while HRV has only the atmospheric circulation component, with SST (sea surface temperature) prescribed from the LRV.

For this study, data from an LRV simulations covering the period from 1850 to 2100 have been extracted. This simulation uses the observed climate parameters from 1850 to 2005 and the rcp45 emission projections for the period 2006-2100. The acronym "rcp45" refers to the family of simulations to be included in the IPCC's 5th Assessment Report, in which a "representative concentration pathway" (rcp) has been specified so that it leads to an approximate radiative forcing of $4.5 \mathrm{~W} \mathrm{~m}^{-1}$ at the end of the 21 st century. In practice, rcp45 represents a moderate rate of warming, consistent with international governments taking significant concerted action for mitigating climate change.

The large computing time needed to run HRV has so far prevented reproducing the whole $1850-2100$ period. This study uses two ensembles of HRV: six 5 yr runs of the present climate (2004-2008) and of the rcp45 scenario at the end of this century (2094-2098) have been performed. Therefore, $30 \mathrm{yr}$ are available at high resolution for both the present climate and the future rcp45 scenario. 


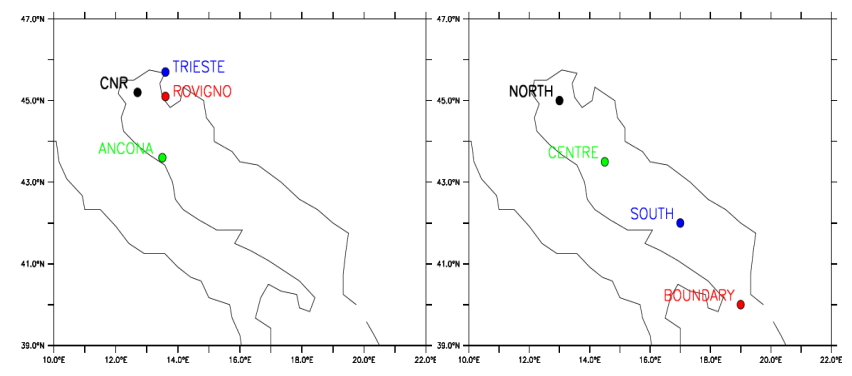

Fig. 1. Adriatic Sea with the 4 points used for the sea level analysis (left panel) and for wind and MSLP analysis (right panel).

\subsection{Storm surge model simulations}

The simulations carried out in this study are based on Hydrostatic Padua Surface Elevation (HYPSE) model, which is a two-dimensional model based on depth averaged currents (Lionello et al., 2005). HYPSE is a standard singlelayer nonlinear shallow water model, whose equations are derived from the vertical average of the momentum equation, assuming a constant velocity profile. It adopts an orthogonal $\mathrm{C}$-grid and uses the leap-frog time integration scheme with the Asselin filter to prevent time splitting.

The model grid covers only the Adriatic Sea. In this study it adopts null elevation as boundary condition in the southeastern area (Otranto Channel), which excludes the effects of sea level fluctuations occurring outside the basin on various time scales. The dependence of the model accuracy on the grid characteristics and resolution has been investigated in a previous study (Lionello et al., 2005). The best results, optimised for the simulation of storm surges at the Venetian coast, are obtained using a rectangular mesh grid of variable size, which has the highest resolution in the northern part of the basin and a logarithmic increment of the mesh size, which varies from a minimum of $3.3 \mathrm{~km}$ at the northern boundary to a maximum of $7 \mathrm{~km}$ at the southern boundary.

The storm surge model runs have been carried out using both LRV and HRV forcings. When using the LRV forcing, decadal statistics of sea level for periods from 1850-2000 (past climate) and 2010-2100 (climate scenario) have been produced. When using the HRV forcing, $30 \mathrm{yr}$ (i.e. six $5 \mathrm{yr}$ long simulations) statistics of sea level both for the present (2004-2008) and the future (2094-2098) scenarios have been computed.

The sea level statistics considers the number of hours above/below values separated by $0.05 \mathrm{~m}$ steps and starting from $0.0 \mathrm{~m}$ at four locations in the Adriatic Sea (Fig. 1, right panel). The most important for this study is the tide gauge located $15 \mathrm{~km}$ offshore the Venice Lagoon on platform ISMAR-CNR $\left(45^{\circ} 19^{\prime} \mathrm{N} ; 12^{\circ} 30^{\prime} \mathrm{E}\right)$, where a long time series of hourly sea level observations is available. The other points are situated in Trieste, Rovigno and Ancona (Fig. 1, left panel). The cumulative distribution has been similarly

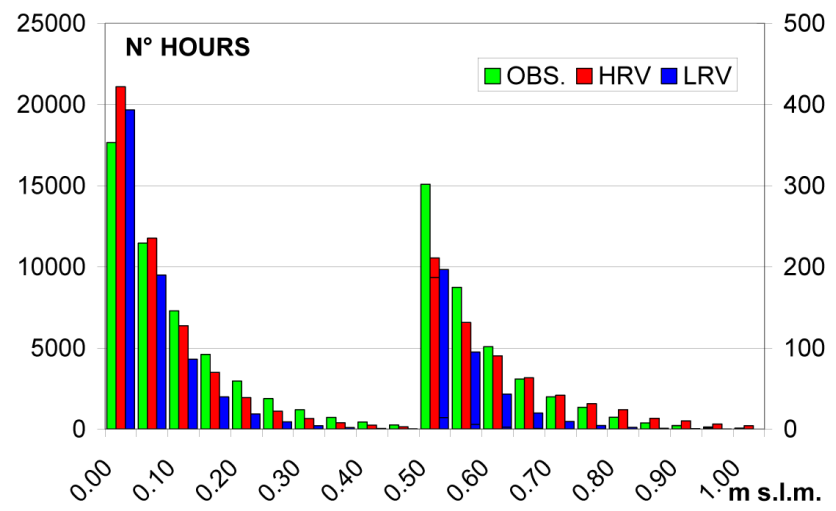

Fig. 2. Cumulated number of hours per decade of water level above fixed thresholds (x-axis) at the ISMAR-CNR platform. HRV (red bars) and LRV (blue bars) simulations are compared with the observations (green bars) of the period 1974-2010. The enlarged scale on the right is used for sea levels $>0.50 \mathrm{~m}$.

computed for wind speed (considering progressively increasing values from the $10 \mathrm{~m} \mathrm{~s}^{-1}$ threshold separated by $1 \mathrm{~m} \mathrm{~s}^{-1}$ steps) steps and for MSLP (considering decreasing values from the $1040 \mathrm{hPa}$ threshold separated by $2 \mathrm{hPa}$ steps). For wind and MSLP the four points shown in the right panel of Fig. 1 are considered.

Statistics were computed for the number of storms as well. A windstorm is here defined as a time duration of at least $30 \mathrm{~h}$ during which the wind speed exceeds a fixed reference level (consequently the number of storms depend on the reference level that is chosen). A similar definition has been adopted for sea level by using, in this case, an $0.20 \mathrm{~m}$ threshold and $0.05 \mathrm{~m}$ step for defining a storm. An analogous concept is used for defining high (low) MSLP events considering steps of $+2 \mathrm{hPa}(-2 \mathrm{hPa})$ from a $1030(1000) \mathrm{hPa}$ threshold.

\subsection{Model validation and importance of resolution}

Model results are compared with observed statistics of sea level data from the tide gauge located outside the Venice Lagoon at platform ISMAR-CNR for the period 1974-2010 (Fig. 2). The influence of the sea level variations originating outside of the Adriatic Sea (about $0.05 \mathrm{~m}$ for the periods with surge $>0$ ) has to be subtracted from the observations to make the data comparable to the model output. A preliminary analysis has shown that decadal surge statistics produced with the LRV forcings show no trend over the whole 1850-2000 period. Therefore, results from the whole period have been used to describe present conditions. For the HRV, the analysis uses the total of $30 \mathrm{yr}$ from an ensemble of six $5 \mathrm{yr}$ long simulations of the 2004-2008 period.

The $10 \mathrm{yr}$ time offset between HRV and LRV and the larger time offset with respect to observations is considered irrelevant because of the steadiness of statistics in LRV. 

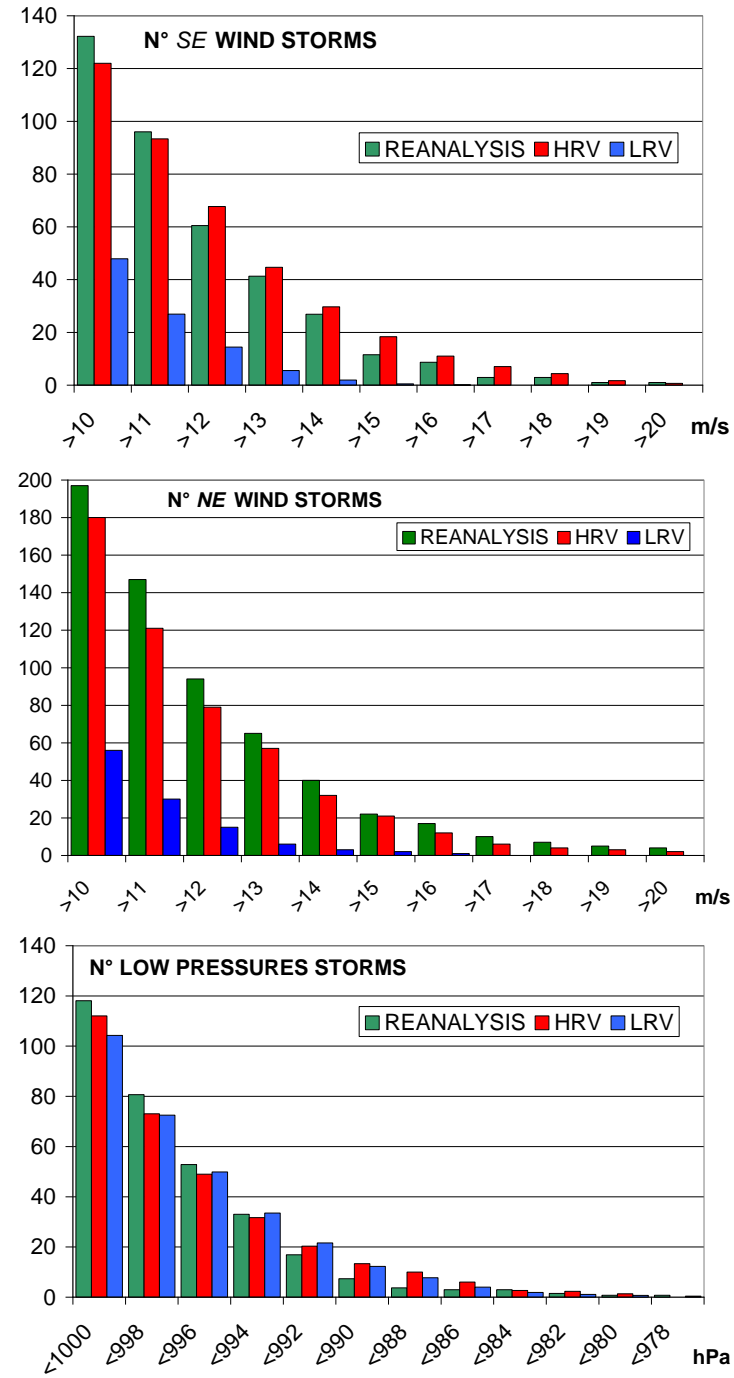

Fig. 3. Number of south-easterly and north-easterly windstorms per decade (top and mid panels) and number of hours per decade below a low-MSLP threshold (bottom panel) for the HRV and LRV simulations and ERA-Interim at the ISMAR-CNR platform.

Figure 2 shows that forcing the surge model with low resolution input meteorological fields does not reproduce adequately sea level statistics in the Northern Adriatic Sea, especially high sea level values. In the LRV-forced simulations no sea level higher than about $0.60 \mathrm{~m}$ occurs, while in observations this threshold is reached for about $200 \mathrm{~h}$ per decade. Clearly, HRV-forced simulations show better statistics than LRV forced simulations and look more reliable for simulating present and future sea level extremes.

The shortcomings of LRV sea level statistics can be traced back to those of winds. In Fig. 3 LRV and HRV statistics are compared with ERA-Interim reanalysis (Dee et al., 2011) wind data, considering the south-easterly component (top panel), which is the main factor producing Venice floods, and

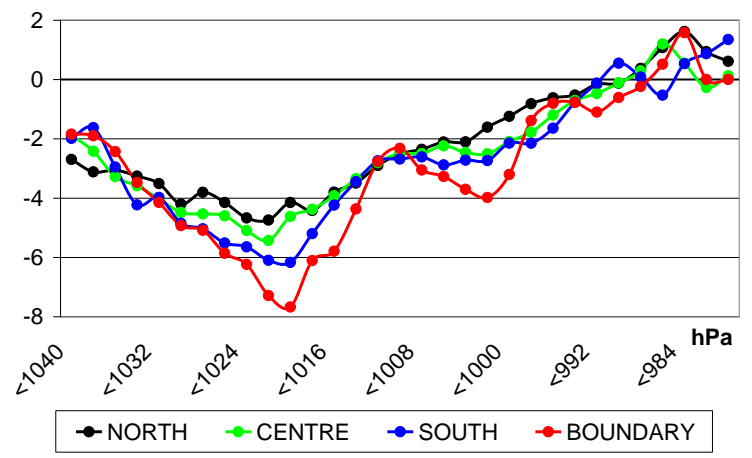

Fig. 4. $t$ test statistics (y-axis) for the cumulated distribution of number of hours below fixed thresholds with $2 \mathrm{hPa}$ step from 980 to 1040 (x-axis) at the four points shown in Fig. 1, left panel. Positive values of the $t$ test statistics indicate that values are higher in the future than in the present period.

the north-easterly (central panel), which has a non-negligible effect. Results show that high resolution is fundamental for approximating the wind speed distribution of ERA-Interim for both components. Conversely, MSLP values (Fig. 3 right panel) are not critically sensitive to the model resolution. This confirms several previous studies on the importance of resolution for correctly modelling wind speed (e.g. Cavaleri and Bertotti, 2004; Lionello et al., 2003).

\section{Results}

In this section a systematic analysis of the climate change signal is carried out by comparing MSLP, wind and sea level cumulated frequency distributions of the HRV simulations in the future (precisely at the end of the 21st century, 20942098) and present (2004-2008) periods. The $t$ test is used for assessing the statistical significance of differences between these two periods. The number of degrees of freedom is estimated with the Welch-Satterthwaite approximation (Motulsky, 1995). As a guideline, for Gaussian variables, absolute values of $t$ larger than 4, 2.5, or 2 imply a $99 \%, 95 \%$ and $90 \%$ confidence level, respectively. Positive values of the $t$ test statistics indicate that frequencies are higher in the future than in the present period.

\subsection{Climate change impact on mean sea level pressure}

MSLP statistics have been computed at four points along the axis of the Adriatic (Fig. 1, right panel). Figure 4 shows the $t$ test statistics for the number of hours below fixed thresholds and shows a significant decrease of the frequency of pressure conditions below a wide range of moderately high values (from 1040 to $1000 \mathrm{hPa}$ ). In other words, the number of hours with pressure values higher than $1000 \mathrm{hPa}$ is projected to significantly increase in the future. The significance of this 


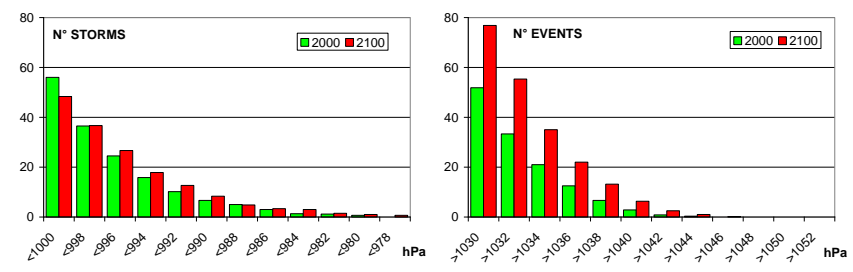

Fig. 5. Cumulated distributions of MSLP events below fixed thresholds (left panel) and high MSLP events above fixed thresholds (right panel) at the ISMAR-CNR platform.

change will be particularly large at the southern boundary of the basin and in the range from $1015 \mathrm{hPa}$ to $1030 \mathrm{hPa}$.

Figure 5 shows the cumulated number of low MSLP events (meaning below fixed thresholds, left panel) and of high MSLP events (meaning above fixed thresholds, right panel) at the ISMAR-CNR platform. A $t$ test (not shown) reveals no significant differences for the frequency of low MSLP events (though low pressure events below the $996 \mathrm{hPa}$ threshold are slightly more frequent at the end of the century), but a very significant increase of high MSLP events.

Figure 6 compares the frequency distribution of the MSLP difference between the ISMAR-CNR platform and the southern boundary of the Adriatic Sea. Positive values indicate a north-westward mean pressure gradient along the axis of the basin. In general, there is no statistically significant difference between the two periods, except for the range from -15 to $-5 \mathrm{hPa}$ denoting a higher frequency of MSLP gradient favouring the wind flow along the axis of the basin and towards its southern boundary ${ }^{1}$. The increase of frequency of opposite conditions (which would eventually lead to the storm surge at the Venetian coast) nearly reach the $90 \%$ confidence level, but remains below it for one bin.

In conclusion, MSLP at the end of the 21st century is projected to increase over the whole Adriatic Sea with respect to present, and there is a small (1\%), but significant, increase in the frequency of situations with north-westward pressure gradient along the main axis of the basin. Therefore in the future the North Adriatic will be characterised by more frequent high MSLP conditions, while an eventual increase pressure gradient favouring storm surge at the Venetian coast is not detected with an acceptable statistical confidence level.

\subsection{Climate change impact on wind}

For wind 12 different directional sectors have been considered, each 30 degrees wide. Though statistics has been computed separately for each sector at three points along the Adriatic Sea (labelled north, centre and south Adriatic in Fig. 1), here only south-easterly (within $120^{\circ}-180^{\circ}$

\footnotetext{
${ }^{1}$ Note that the presence of the mountain ridges on both sides of the Adriatic Sea implies a strong channelling effect and departure from the geostrophic balance.
}

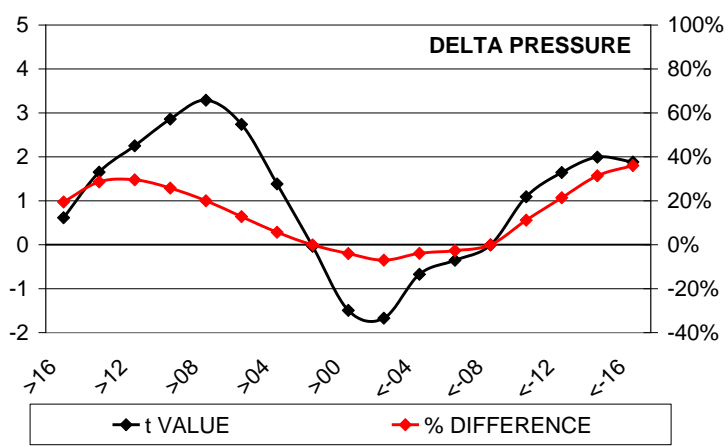

Fig. 6. $t$ test statistics (black line and left y-axis) for the change of number of hours per decade as function of the MSLP difference between the northern part and the southern boundary of the Adriatic Sea. The red line shows difference (\%, right y-axis) in the number of hours. Positive values indicate situations in which MSLP is higher at the southern boundary of the Adriatic Sea then in the north.

clockwise to the north) and north-easterly (within $0^{\circ}-60^{\circ}$ clockwise to the north) winds are considered, because they cause most of storm surges in the Adriatic Sea (particularly the south-easterly winds).

Figure 7 shows the $t$ test statistics for the number of hours (left column) and the number of storms (right column) above fixed thresholds. The upper row considers all wind directions, the middle and lower rows consider only south-easterly and north-easterly winds, respectively. A significant future decrease of conditions related to low and moderate wind speed (up to $12 \mathrm{~m} \mathrm{~s}^{-1}$ ) is found for all directions. This substantial decrease takes place at the expenses of the windless hours (here considered the hours with wind speed lower than $1 \mathrm{~m} \mathrm{~s}^{-1}$ ), whose frequency is projected to be $13 \%$ higher in the future than in the present at a confidence level larger than $95 \%$. These changes in the wind are consistent with the increased persistence of high pressure conditions resulting from the analysis is Sect. 3.1. Note that the decrease of hours attributed to the south-easterly wind is consistent with the behaviour of the pressure gradient in Fig. 6 and it is particularly significant at the southern boundary. In general, the effect of climate change on high wind speed conditions, which are expected to be responsible for high storm surges, is not statistically significant and most changes are below the commonly accepted minimum $90 \%$ confidence level.

The overall future scenario suggests an increased frequency of windless conditions, a weaker than now atmospheric circulation both in the north-easterly and southeasterly directions, with, possibly, some change in the frequency of the various wind regimes and a higher variability in the north (as suggested by the increased number of windstorms). However, this last statement does not reach a convincingly high statistical level. There is qualitative agreement with previous results (Pasaric and Orlic, 2004) on future weakening of atmospheric circulation, particularly of the north-easterly component. 

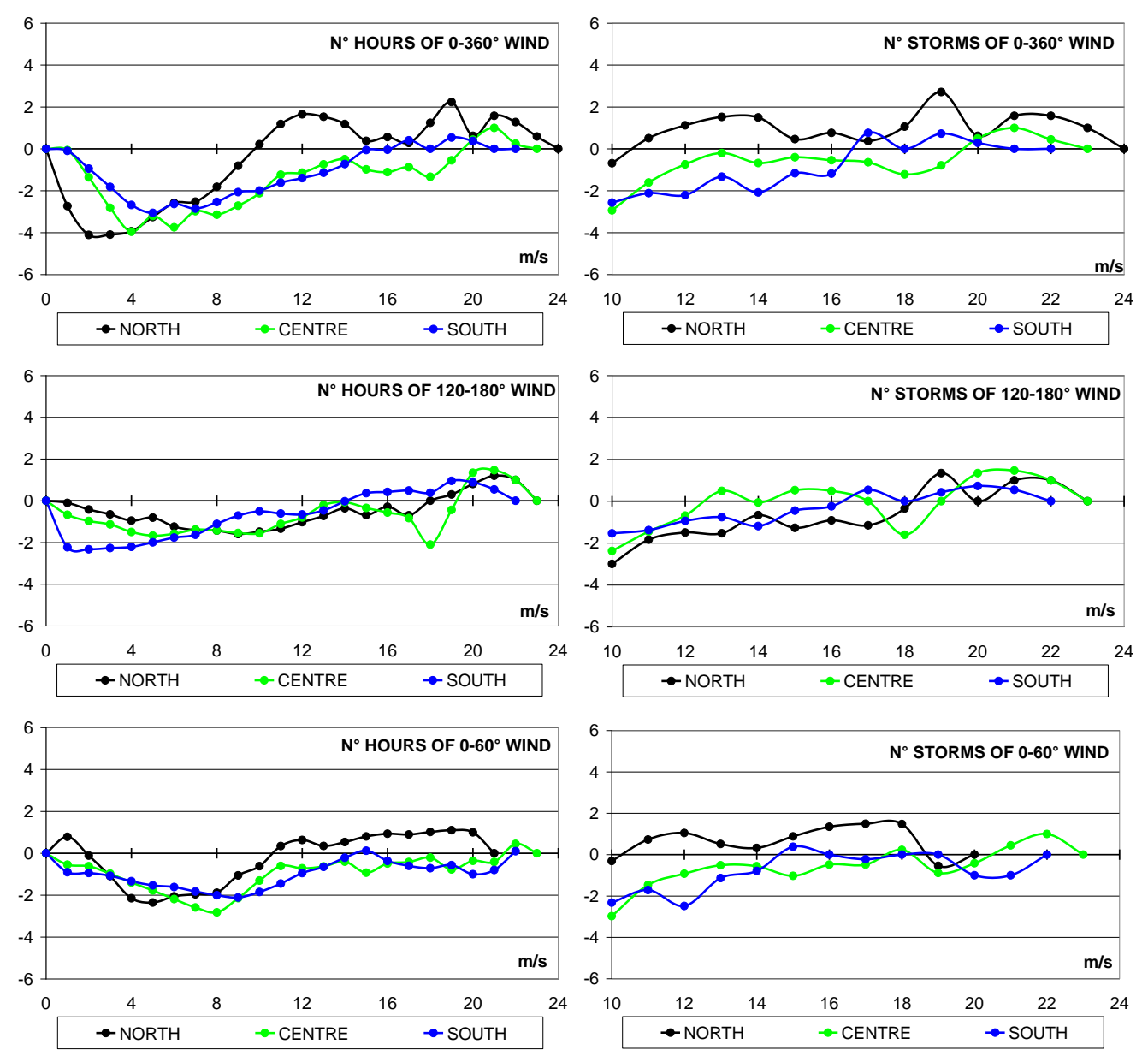

Fig. 7. $t$ test statistics for cumulated number of hours above fixed wind speed thresholds (left side column) and for the number of storms (right column) at the north, centre and south points in Fig. 1. Upper row considers all wind directions, central row considers south-easterly winds $\left(120-180^{\circ}\right)$, bottom row north easterly winds $\left(0-60^{\circ}\right)$. Positive values of the $t$ test statistics indicate that frequencies are higher in the future than in the present period.

\subsection{Climate change impact on sea level}

Sea level variability at the Venetian coast responds to that of the wind and MSLP fields over the whole basin. The intensity of this response is not uniform, and particularly for wind, the sensitivity is expected to be higher to its changes in the northern shallow part of the basin. This subsection attempts to identify effects of the relatively small changes in the forcing, which fields have been discussed in the two previous sections, on sea level.

Figure 8 shows the cumulated distribution of the number of hours (left panel) and number of storms (right panel) above fixed sea level threshold in present and future climate conditions at the ISMAR-CNR platform. This figure shows a future reduction of number of hours and storm, which is coherent across a wide range of thresholds and consistent both with the mild attenuation of wind regimes (involving the north-easterly and south-easterly components, as it is shown in Fig. 7) and with the increased frequency of high MSLP conditions. However, no difference between present and future climate condition is statistically significant, not even with a low confidence level (less than $90 \%$ ). Figure 9 shows the $t$ test statistics at the four station in Fig. 1 (left panel) and similarly suggests that no significant climate change signal in sea level is present in these simulations in the whole northern part of the Adriatic Sea.

Therefore, this analysis concludes that, though future changes of atmospheric circulation over the Adriatic Sea can be identified, those of the surface wind components responsible for storm surges and of the MSLP are too small to effectively affect the statistics of storm surges at the Venetian coast. 

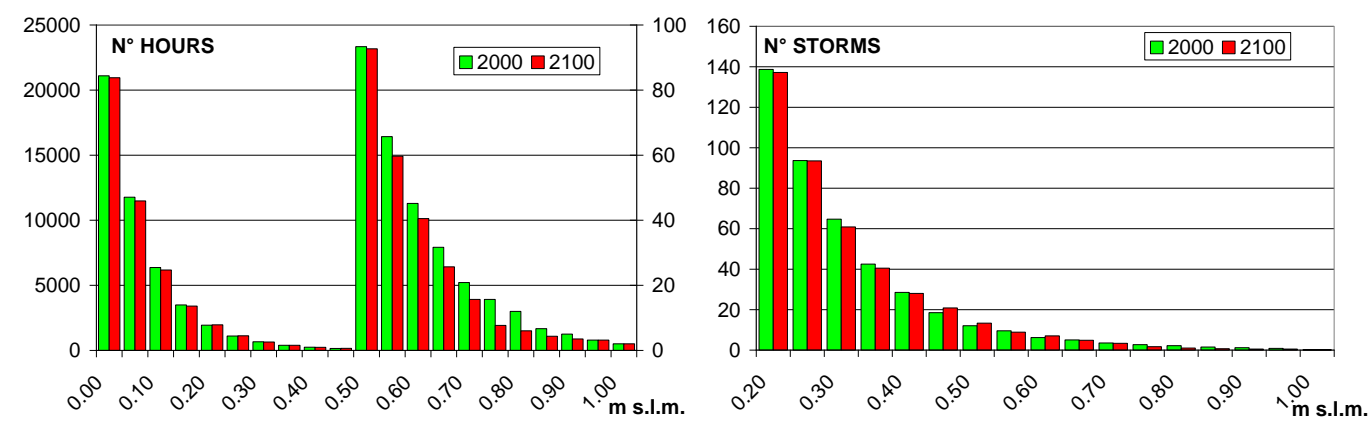

Fig. 8. Cumulated distribution of the number of hours (left panel, the enlarged scale on the right is used for sea levels above $0.50 \mathrm{~m}$ ) and number of storms (right panel) above fixed sea level thresholds in present and future climate conditions at the ISMAR-CNR platform.
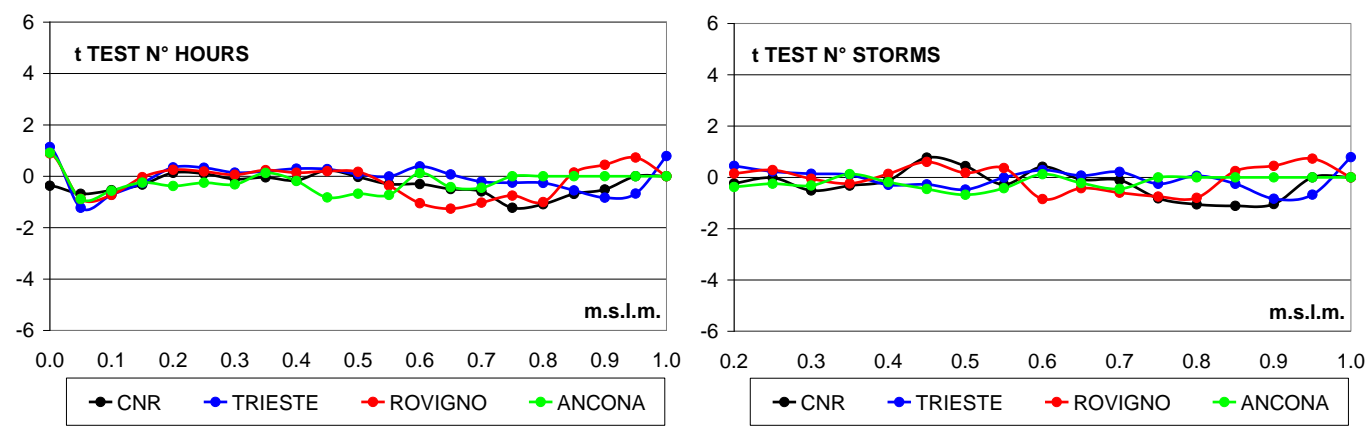

Fig. 9. $t$ test for the cumulated distribution of the number of hours (left panel) and of storms (right panel) above fixed sea level thresholds at the four locations shown in Fig. 1a.

\section{Summary and conclusions}

New data from the high resolution global model EC Earth v. 2.3 are used to analyze the climate change effect on storm surge levels at Venice and in the Adriatic Sea. The rcp45 scenario is used, producing a six member ensemble of $5 \mathrm{yr}$ runs, both for present (2004-2008) and future (2094-2098) climate conditions. MSLP and wind are analysed at four points along the Adriatic Sea, with a special care paid to meteorological situations favourable to storm surges in the Venice Lagoon. The statistical significance of differences between future and present conditions is assessed by a $t$ test. Wind and MSLP fields from the climate model simulations are used to drive a hydrostatic storm surge model (HYPSE) in the Adriatic Sea to investigate the importance of the climate change signal for storm surge levels. Results at the ISMAR-CNR platform (close to Venice and equipped with a long series of observed data) and three other points in the northern part of the Adriatic Sea are considered.

Results present no statistical evidence of changes of storm surge statistics in the future climate scenario. This confirms previous studies (Lionello et al., 2003, 2012b; Lionello, 2005) and shows that likely the main hazard to the north Adriatic flat coast and to Venice is posed by future sea level rise and not by an increasing number of storms. Actually, this study shows that other parameters, like wind and MSLP, are likely to change in the future. An increase of the frequency of windless conditions, a decrease of the frequency of moderate winds and an increase of the frequency of high MSLP conditions is found. However, these changes of wind and MSLP climate have little effect on the frequency of surges (which are sensitive mostly to high wind speeds) and do not cause changes of storm surge frequencies.

Admittedly, our study suffers from some limitations. This approach filters out the effects of sea level variability developing on the scale surpassing that of the Adriatic Sea. In principle this limitation could be mitigated adopting different open boundary condition (e.g. Davies and Flather, 1977) across the Otranto Channel, which should eventually involve nesting an Adriatic Sea grid within a coarser grid including the Ionian Sea or possibly the whole Mediterranean Sea. However, the effect of sea level variability in the deep water conditions outside the Adriatic Sea is mainly related to MSLP forcing. Therefore, it is not strongly affected by model resolution (which is the main focus of this study). The most obvious approach to its description would be to use a grid at lower resolution, but covering the whole Mediterranean Sea. Another limitation of this study is that it is based on a single climate model. Future research should obviously consider simulations carried out with other climate models as this is an 
essential issue in this type of study (Woth et al., 2006; Lowe and Gregory, 2008). Furthermore, since the simulated scenario (rcp45) adopts a moderate increase of anthropogenic emissions, it is important to investigate other scenarios (if high resolution simulations will be available).

Acknowledgements. The authors thank to Dario Conte for the assistance in solving computer problems and the management of input fields. The hourly sea level observation at the CNRPLATFORM were kindly provided by I.C.P.S.M. of the Venice City Council.

Edited by: L. Bertotti

Reviewed by: A. Tomasin, M. Orlic, and one anonymous referee

\section{References}

Bock, Y., Wdowinski, S., Ferretti, A., Novali, F., and Fumagalli A.: Recent subsidence of the Venice Lagoon from continuous GPS and interferometric synthetic aperture radar, Geochem. Geophys. Geosyst., 13, Q07008, doi:10.1029/2012GC004191, 2012.

Canestrelli, P., Mandich, M., Pirazzoli, P. A., and Tomasin, A.: Wind, depression and seiches: tidal perturbations in Venice (1951-2000), Città di Venezia, Centro Previsioni i Segnalazioni Maree, Comune di Venezia, 1-104, 2001.

Cavaleri, L. and Bertotti, L.: Accuracy of the modelled wind and wave fields in encloses seas, Tellus, 56A, 167-175, 2004.

Davies, A. M. and Flather, R. A.: Computation of the storm surge of 1 to 6 April 1973 using numerical models of the North West European continental shelf and the North Sea, Deutsch. Hydrogr. Z., 30, 139-162, 1977.

Dee, D. P., Uppala, S. M., Simmons, A. J., Berrisford, P., Poli, P., Kobayashi, S., Andrae, U., Balmaseda, M. A., Balsamo, G., Bauer, P., Bechtold, P., Beljaars, A. C. M., van de Berg, L., Bidlot, J., Bormann, N., Delsol, C., Dragani, R., Fuentes, M., Geer, A. J., Haimberger, L., Healy, S. B., Hersbach, H., Hólm, E. V., Isaksen, L., Kållberg, P., Köhler, M., Matricardi, M., McNally, A. P., Monge-Sanz, B. M., Morcrette, J.-J., Park, B.-K., Peubey, C., de Rosnay, P., Tavolato, C., Thépaut, J.-N., and Vitart, F.: The ERA-Interim reanalysis: configuration and performance of the data assimilation system, Q. J. R. Meteorol. Soc., 137, 553-597, doi:10.1002/qj.828, 2011.

Hazeleger, W., Severijns, C., Semmler, T., Stefanescu, S., Yang, S., Wang, X., Wyser, K., Dutra E., Baldasano, J. M., Bintanja, R., Bougeault, P., Caballero, R., Ekman, A. M. L., Christensen, J. H., van den Hurk, B., Jimenez, P., Jones, C., Kallberg, P., Koenigk, T., McGrath, R., Miranda, P., van Noije, T., Palmer, T., Parodi, J. A., Schmith, T., Selten, F., Storelvmo, T., Sterl, A., Tapamo, H., Vancoppenolle, M., Viterbo, P., and Willen, U.: EC-Earth: A Seamless Earth-System Prediction Approach in Action, Bull. Am. Meteor. Soc., 91, 1357-1363, doi:10.1175/2010BAMS2877.1, 2010.

How, W. S., Muhaman, H., Tangang, F. T., and Juneng, L.: Projection of Storm Surge Climate Extreme over Sunda Shelf Based on IPCC SRES A2 Scenario, Sains Malaysiana, 41, 1411-1422, 2012.
Lionello, P.: Extreme surges in the Gulf of Venice, Present and Future Climate, in: Venice and its lagoon, edited by: Fletcher, C. and Spencer, T., State of Knowledge Cambridge University Press, Cambridge UK, 59-65, 2005.

Lionello, P.: The climate of the Venetian and North Adriatic region: Variability, trends and future change, Phys. Chem. Earth, 40-41, $1-8,2012$.

Lionello, P., Elvini, E., and Nizzero, A.: A procedure for estimating wind waves and storm-surge climate scenarios in a regional basin: the Adriatic Sea case, Climate Res., 23, 217-231, 2003.

Lionello, P., Mufato, R., and Tomasin, A.: Sensitivity of free and forced oscillations of the Adriatic Sea to sea level rise, Climate Res., 29, 23-39, 2005.

Lionello, P., Cavaleri, L., Nissen, K. M., Pino, C., Raicich, F., and Ulbrich, U.: Severe marine storms in the Northern Adriatic: Characteristics and trends, Phys. Chem. Earth, 40-41, 93-105, doi:10.1016/j.pce.2010.10.002, 2012a.

Lionello, P., Galati, M. B., and Elvini, E.: Extreme storm surge and wind wave climate scenario simulations at the Venetian littoral, Phys. Chem. Earth, 40-41, 86-92, doi:10.1016/j.pce.2010.04.001, 2012b.

Lowe, J. A. and Gregory, J. M.: The effect of climate change on storm surges around the United Kingdom, Phil. Trans. R. Soc., 363, 131-1328, doi:10.1098/rsta.2005.1570, 2008.

Lowe, J. A., Gregory, J. M., and Flather, R. A.: Changes in the occurrence of storm surges around the United Kingdom under a future climate scenario using a dynamic storm surge model driven by the Hadley Centre climate models, Clim. Dynam., 18, 179188, 2001.

Motulsky, H.: Intuitive Biostatistics, Oxford Univ. Press, 201-209, 1995.

Pasaric, M. and Orlic, M.: Meteorological forcing of the Adriatic - present vs. projected climate conditions, Geofizika, 21, 69-87, 2004.

Robinson, A. R., Tomasin, A., and Artegiani A.: Flooding of Venice, phenomenology and prediction of the Adriatic storm surge, Q. J. R. Meteorol. Soc., 99, 688-692, 1973.

Scarascia, L. and Lionello, P.: Global and regional factors contributing to the past and future sea level rise in the Adriatic Sea, doi:10.1016/j.gloplacha.2013.03.004, in press, 2013.

Sterl, A., van den Brink, H., de Vries, H., Haarsma, R., and van Meijgaard, E.: An ensemble study of extreme storm surge related water levels in the North Sea in a changing climate, Ocean Sci., 5, 369-378, doi:10.5194/os-5-369-2009, 2009.

Trigo, I. F. and Davies, T. D.: Meteorological conditions associated with sea surges in Venice: a 40 year climatology, Int. J. Climatol., 22, 787-803, 2002.

Woth, K., Weisse, R., and von Storch, H.: Climate change and North Sea storm surge extremes: an ensemble study of storm surge extremes expected in a changed climate projected by four different regional climate models, Ocean Dynam., 56, 3-15, doi:10.1007/s10236-005-0024-3, 2006.

Ziehmann, C.: Skill prediction of local weather forecasts based on the ECMWF ensemble, Nonlin. Processes Geophys., 8, 419-428, doi:10.5194/npg-8-419-2001, 2001. 